Thorax, 1980, 35, 151-153

\title{
Intrapericardial aneurysm of the left atrial appendage
}

\author{
TATSUZO TANABE, MASANORI ISHIZAKA, SATOMI OHTA, \\ AND SABURO SUGIE \\ From the Second Department of Surgery, Hokkaido University School of Medicine, \\ Sapporo, Japan
}

ABSTRACT A 24-year-old housewife with congenital aneurysm of the left atrial appendage underwent a successful operation for its removal. Operation, using cardiopulmonary bypass, is indicated in all patients with atrial aneurysm. The procedure has proved uniformly safe and successful.

Aneurysmal dilatation of the left atrium as a consequence of valvular heart disease is common. However, congenital or idiopathic aneurysm of the left atrium is extremely rare. Twenty-six cases verified at necropsy or operation have been reported. The purpose of this report is to present a case of congenital aneurysm of the left atrial appendage.

\section{Case report}

A 24-year-old housewife was admitted to hospital in April 1976 with attacks of palpitation and atrial fibrillation. At age 10 years she was told that she had an enlarged heart and congenital heart disease was suggested. Attacks of palpitation were experienced for the first time at 18 years. Subsequent attacks of palpitation occurred frequently and lasted longer, and she received treatment with digitalis and DC conversion without any benefit. She was admitted to Hokkaido Unjversity Hospital on 10 April 1976 for investigation.

The patient was a well-developed woman. On admission her pulse was irregular at 80 beats per minute. The pulses were present in all extremities, and the blood pressure was $126 / 60 \mathrm{~mm}$ mercury. There was no cyanosis or clubbing of digits. On auscultation, the heart sounds were normal, and no murmur was heard. The chest radiograph showed cardiac enlargement (CTR 61.5\%), with a prominent convexity located at the left cardiac border in the position of the left atrial appendage (fig 1). A barium swallow showed no posterior

Address for reprint requests: Dr T Tanabe, Second Department of Surgery, Hokkaido University Hospital, Sapporo, Japan 060. displacement of the oesophagus. The electrocardiogram showed atrial fibrillation only. There was no evidence of ventricular hypertrophy. The echocardiographic scan revealed a large cavity behind the left ventricular wall. Cardiac catheterisation revealed that all intracardiac pressures were within normal limits and there was no evidence of an intracardiac shunt. Cardioangiography demonstrated a huge nonpulsating dilatation of the left atrial appendage from which the contrast medium cleared slowly. The left atrium and the left ventricle were displaced to the right by the dilated left atrial appendage. The diagnosis after cardiac catheterisation was congenital aneurysm of the left atrial appendage.

An operation was perfomed on 23 June 1976,

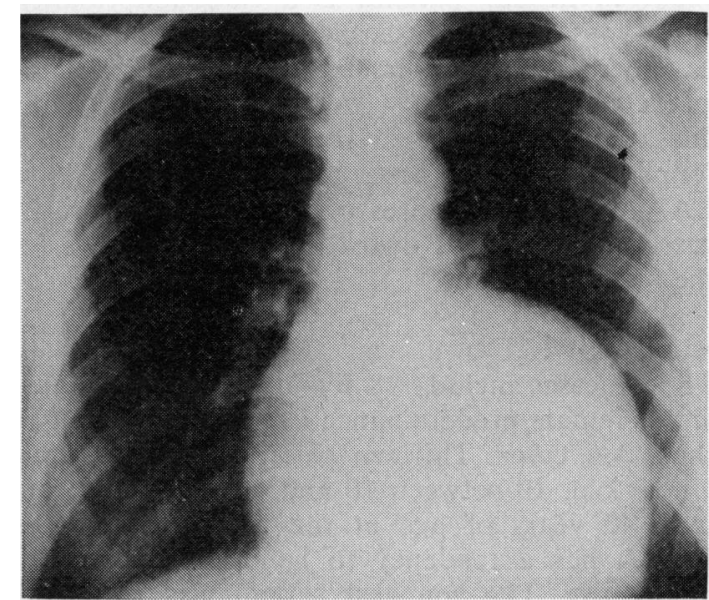

Fig 1 Preoperative chest radiograph. 
through a median sternotomy. The pericardium was intact. A large intrapericardial mass, approximately $10 \times 10 \times 12 \mathrm{~cm}$ was seen adjacent to the left ventricle (fig 2). The mass was nonpulsatile, soft, and compressible. A broad communication $5 \times 2 \mathrm{~cm}$ connected the mass and the left atrium. To prevent embolisation of thrombus, cardiopulmonary bypass was begun, a left ventricular vent was inserted, and the aorta was clamped before the mass was manipulated. The mass was then opened and excised, and the left atrium was closed with 3-0 Tevdek sutures by imbricating the cut edges to make two layers.

There was no evidence of stenosis or incompetence of the mitral valve. After an uneventful postoperative course, the patient was discharged on 26 July 1976, in sinus rhythm. She was seen as an outpatient one year later symptom-free, in sinus rhythm and with a normal chest radiograph. The specimen showed an extremely thin left atrial appendage containing thrombus.

\section{Discussion}

Aneurysmal enlargement of the left atrium occurs in two forms, an intrapericardial type with an intact pericardium and an extrapericardial type in association with a pericardial defect. ${ }^{1}$ However, these two types are thought to be two separate disease entities.

The extrapericardial type is primarily a deficiency of a portion of the pericardium through which the left atrium may herniate. The intrapericardial type is considered to be caused by congenital abnormalities of the left atrial wall. ${ }^{2}$

Intrapericardial left atrial aneurysm, such as occurred in our patient, is a rare abnormality. Two types of intrapericardial left atrial aneurysms have been described-aneurysmal dilatation of the left atrial appendage (LAAA), and aneurysmal dilatation of the left atrial wall (LAA). We have found reports of 26 cases consisting of 14 cases of LAAA $^{3-15}$ and 12 cases of LAA. ${ }^{216-25}$ These 27 cases, including our own case, form the basis for the following review.

\section{AGE AND SEX}

The 27 cases include 18 females and nine males, and a female predominance is noted, especially in the LAA cases. Thirteen patients were less than 1 year old, 10 between 10 and 40 years, and four over 40 years of age at the time of diagnosis. LAAA has a tendency to be discovered at the higher age. The youngest patient was 7 months, the oldest 68 years.

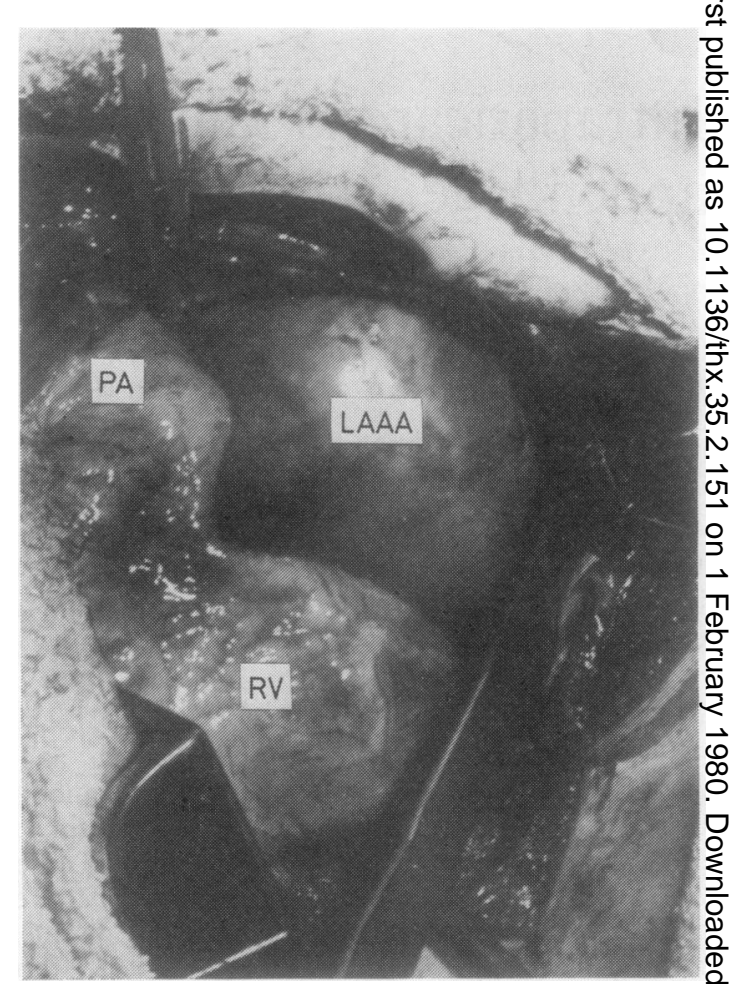

Fig 2 Appearance of the left atrial aneurysm through the median sternotomy incision. LAAA=left atrial appendage aneurysm, $P A=$ pulmonary artery, $R V=$ right ventricle.

\section{SYMPTOMS}

Palpitations with arrhythmias were described i 10 patients and were the chief complaint. Cereo bral embolism was reported in six patients. Three of the patients had more than one embolic epio sode. Cerebral embolus was the first symptom i three patients, and was the only complaint if two. A faint systolic murmur was heard along the left sternal border in 16 patients and a systolie. and diastolic murmur was heard at the apex in three patients.

\section{ELECTROCARDIOGRAM}

The electrocardiogram was normal in nine patients. Seven patients had atrial fibrillation four atrial enlargement, and three persistent supraventricular tachycardia. Two patients showe changes compatible with an atrial septal defect of secundum type.

\section{CHEST RADIOGRAPH}

In all patients the plain chest radiograph showed a mass protruding superiorly and to the left be् 
tween the pulmonary artery and the left ventricle. Angiocardiography was performed on 22 patients and confirmed the diagnosis in 17. An incorrect diagnosis was made of three intracardiac tumours, two ventricular aneurysms, and one "suspicion of left ventricular disease". The differential diagnosis of intrapericardial left atrial aneurysm and extrapericardial left atrial hypertrophy is sometimes difficult. Both lesions may have similar symptoms, electrocardiograms, and chest radiographs. Deficiency of the pericardium in the extrapericardial type may be diagnosed with the help of the electrocardiogram, angiography and a leftsided diagnostic pneumothorax. ${ }^{26}{ }^{27}$

\section{TREATMENT}

Operation was carried out in 22 patients. The aneurysm was removed without difficulty with an uneventful postoperative course in 17 out of 20 patients. In the patient with multiple aneurysms a small cerebral embolus occurred. In two patients the aneurysm was not removed at the first operation. Reoperation was necessary on account of cerebral embolus. The aneurysms were sutured in two patients, but one died of a cerebral embolus.

Atrial aneurysm is not a benign condition. Major cerebral embolism and congestive heart failure with supraventricular tachycardia have occurred in many patients. Operation is indicated in all patients with atrial aneurysm. The procedure has proved uniformly safe and curative. Operation should be done using cardiopulmonary bypass and the aneurysm should be removed.

\section{References}

1 Williams WG. Dilatation of the left atrial appendage. Br Heart J 1963; 25:637-43.

2 Shaher RM, Anis W, Alley R, Mintzer J. Con. genital enlargement of the left atrium. $J$ Thorac Cardiovasc Surg 1972; 63:292-9.

3 Palacio J, Guido JJ, Noger VN et al. Megaorejve izquierda congenita. Prensa Med Argent 1960; 47:1505-11.

4 Parmley CF. Congenital atriomegaly. Circulation 1962; 25:553-8.

5 Williams WG. Dilatation of the left atrial appendage. Br Heart J 1963; 25:637-43.

6 Godwin TF, Auger P, Key JA, Wigle ED. Intrapericardial aneurysmal dilatation of the left atrial appendage. Circulation 1968; 37:397-401.

7 Sloman G, Hunt D, Hare S. Aneurysmal dilatation of the left appendage. Med J Aust 1969; 2:101-2.

8 Hall J, Dobbs RH. Cerebral emboli from aneurysm of left atrial appendage. Proc $R$ Soc Med 1969; 62:911.
9 Salonikides N, Tsakonas P, Gazetopoulos N, Katsonis S, Manes M. Dilatation aneurysmale congenitale de l'auricule gauche. Acta Cardiol 1970; 25:188-96.

10 Sanderud A, Garman D, Hatle L, Rokseth R. Aneurysmal dilatation of the left auricle. Scand J Thorac Cardiovasc Surg 1971; 5:143-6.

11 Eie H, Semb G, Müller O, Holm HA. Aneurysm of the left atrial appendage. Scand $J$ Thorac Cardiovasc Surg 1972; 6:149-53.

12 Behrendt DM, Aberdeen E. Congenital aneurysm of the left atrium. Ann Thorac Surg 1972; 13: 54-59.

13 Hansen JF, Rygg I, Efsen F. Intrapericardial left atrial aneurysm. Am Heart $J$ 1974; 87:113-6.

14 Amato JJ, Sewell H, Rheinlander HF, Cleveland RJ. Congenital aneurysm of the left atrium with associated defects in the fibrous skeleton of the heart. J Thorac Cardiovasc Surg 1975; 69:639-43.

15 Krueger SK, Ferlic RM, Mooring PK. Left atrial appendage aneurysm. Correlation of noninvasive with clinical and surgical findings. Circulation 1975; 52:732-8.

16 Semans JH, Taussig HB. Congenital "aneurysmal" dilatation of the left auricle. Bull Johns Hopkins Hosp 1938; 63:404-14.

17 Pitts RM, Potts WJ. Congenital diverticulum of the left atrium. Arch Surg 1962; 84:334-6.

18 Hebert WM, Arismendi L, Ruhstaller H, Petersen, HC. Aneurysm of left atrium associated with syncope and cyanosis. J Thorac Cardiovasc Surg 1965; 49:535-9.

19 Parker JO, Connell WF, Lynn RB. Left atrial aneurysm. Am J Cardiol 1967; 20:579-82.

20 Macleod CA, Ankeney JL, Perrin EV, Nickel SS, Liebman J. Left atrial aneurysm. Am Heart J 1970; 80:683-8.

21 Ando M, Mori K, Takao A, Ebina K. Idiopathic dilatation of the left atrium. Shinzo (Heart) 1970; 2:449-58.

22 Hougen TJ, Mulder DG, Gyepes MT, Moss AJ. Aneurysm of the left atrium. Am J Cardiol 1974; 33:558-61.

23 Wang T, Anagnostopoulos CE, Resnekov L. Aneurysm of the body of the left atrium presenting with chest pain. Chest 1975; 67:226-8.

24 Tomisawa $M$, Onouchi $E$, Goto $M$ et al. Congenital left atrial enlargement: a case report with special reference to myocardial fine structure. Jap Circulation J 1975; 39:417-24.

25 Iwaya K, Kokubun R, Sato $\mathrm{Y}$ et al. A case of left atrial wall aneurysm with congenital mitral insufficiency. Shinzo (Heart) 1976; 8:650-6.

26 Dimond, EG, Kittle CF, Voth DW. Extreme hypertrophy of the left atrial appendage, the case of the giant dog ear. Am J Cardiol 1960; 5:122-5.

27 Hering AC, Wilson JS, Ball RE Jr. Congenital deficiency of the pericardium. $J$ Thorac Cardiovasc Surg 1960; 40:49-55. 